\title{
El SeCretario del Rey, ANTONio de Aróstegui, A LA LUZ de SU Testamento: LA PERSONA Y EL PERSONAJE
}

\author{
María José Collado Ruiz \\ Universidad de Granada
}

RESUMEN: Este trabajo pretende sacar a la luz una de las figuras más desconocidas del entorno de Felipe III, su secretario Antonio de Aróstegui. Su dedicación a las tareas oficiales y la promoción de dos importantes construcciones en Granada, el convento de los agustinos descalzos y su casa en el Padul.

Palabras clave: Secretario, Felipe III, Granada, convento.

ABSTRACt: This work aims to bring to light one of the most unknown persons of the environment of Felipe III, his secretary Antonio de Aróstegui. His dedication to the official tasks and the promotion of two major buildings in Granada, the convent of the Discalced Augustinians and the Padul home.

Keywords: Secretary, Philipp III, Granada, convent.

\section{INTRODUCCIÓN}

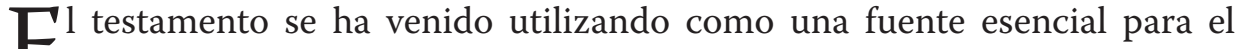
Eestudio de la religiosidad de un periodo concreto. Pero la religiosidad es uno más de los múltiples aspectos que pueden dejarse traslucir a través de este tipo de documento. En él se ha querido ver en ocasiones su carácter espiritual, que lo tiene, pero no en exclusiva. Ya que si bien es cierto que queda obligatoriamente enmarcado en las pautas a seguir para tener una buena muerte cristiana en una sociedad tan ritualizada como la del Antiguo Régimen 
e incluso concediéndole el carácter así expresado por los mismos autores legales de la época como documento religioso. ${ }^{1}$ No deja de ser en esencia, como lo es en la actualidad, un documento de transmisión patrimonial.

Aun así, en él se pueden percibir sutiles referencias a la realidad más privada del testador. El lenguaje protocolizado con que se expresa responde a los impuestos moldes formales de los manuales notariales, sin embargo, la convicción y cercanía de la muerte hace que entre líneas se cuelen esas voluntades últimas y los anhelos más profundos del que se sabe próximo a su fin terrenal. Lo que tampoco significa que se deba analizar exclusivamente como un testimonio íntimo y personal.

Cualquiera de las caracterizaciones que se le den a este documento deben ser tenidas en cuenta con extrema cautela, ya que sin duda su excepcional valía radica en mostrarse como un testimonio capaz de analizarse desde distintos puntos de vista, ofreciendo una realidad poliédrica e identificando al testador como un sujeto individual perfectamente enmarcado en las coordenadas de su tiempo.

Se hace necesaria esta aclaración previa, dado que la naturaleza del documento tomado como base de este trabajo, es el traslado autentificado del testamento cerrado que don Antonio de Aróstegui otorgó en Madrid el 13 de febrero de 1623 y el codicilo que añade el día diecinueve del mismo mes. Ambos forman parte de un expediente que se abrió en uno de los tribunales que el Arzobispado de Granada, el dedicado al control y fiscalización de testamentos, patronatos y obras pías y que, por tanto, se encargó del seguimiento de algunas fundaciones que habían sido instituidas vía testamentaria. ${ }^{2}$ Tras su lectura será posible realizar un acercamiento, al menos a una doble caracterización de D. Antonio de Aróstegui: como persona y como personaje.

\section{El secretario del rey, Antonio de Aróstegui, en su testamento}

Tal y como se prescribe para cualquier tipo de documento contractual, y el testamento no es una excepción, al principio constará la identificación del otorgante. En este caso, don Antonio de Aróstegui, quien en su presentación obviará cualquier tipo de filiación familiar y se ceñirá a la enumeración de dignidades alcanzadas. En primer lugar, y seguramente, el orden es importante, señala su pertenencia a la antigua orden religioso-militar de Santiago, lo que sin duda todavía en el siglo Xvir le suponía un estatus de privilegio y un reconocimiento basado en la valía de su linaje en términos de honor. A esto

1. Pedro Melgarejo, Compendio de contratos públicos, autos de particiones, executivos y de residencias con el género del papel sellado que a cada despacho toca, Ed. de Herederos de Gabriel de León, Madrid, 1647, p. 84. Explica que testar «es un acto religiosísimo».

2. AhdGr, Sec. Patronatos, leg. 553-E (3), El expediente sobre algunas fundaciones piadosas de Antonio de Aróstegui se conserva en la signatura referenciada, y en lo sucesivo las citas de su testamento y codicilo no se repetirán como nota para facilitar la lectura fluida del presente artículo. 
le añade la posesión de una encomienda de esta orden, la de Santo Coloiro en Sicilia. ${ }^{3}$ Ahora bien, estos honores se encuentran supeditados en buena medida a la actuación personal llevada a cabo en el entorno de la corte. Por tanto, relacionará sus cargos, formando parte del Consejo de Guerra y como secretario de Estado del monarca. Lo que explica que tenga fijada su residencia en la ciudad de Madrid, donde está otorgando testamento.

Es la muestra más evidente del cambio operado entre la nobleza hispana, la asunción de un nuevo rol que queda cada vez más alejado de los alardes guerreros y territoriales del Medievo, que se institucionaliza a la par que la administración de un incipiente estado moderno. $Y$ es justo en ese proceso donde tiene cabida el mostrarse en un documento de últimas voluntades como una persona cercana al máximo dirigente, en este caso el rey, perteneciendo a las instituciones que le asistían y en quien delegaba parte de sus actuaciones de gobierno, como podía ser un secretario de Estado. Sin embargo, en esta circunstancia se ha de ser muy cauteloso, ya que está todavía por determinar cuál fue el papel que pudo jugar Antonio de Aróstegui durante el reinado de Felipe III y los pocos años que vivió del de Felipe IV.

Las instituciones a las que dice pertenecer, el Consejo de Guerra y de Estado gozaron de una etapa de renovación y resurgimiento con la subida al trono de Felipe III. Sin embargo, en el largo periodo que se ha dado en denominar de los Austrias menores, caracterizado por el encumbramiento de grandes personajes que hicieron de su ambición, el principal rasgo de su personalidad y se aprovecharon de la escasa intervención directa del rey en los asuntos de Estado y de los subterfugios de poder que les proporcionaba la compleja administración de los extensos territorios hispanos, Antonio Aróstegui parece estar en un discreto segundo plano. A pesar de haber sido nombrado secretario del rey en 1600, su bajo perfil político no lo ha hecho merecedor por el momento de grandes esfuerzos por parte de los investigadores. ${ }^{4}$

La tradicional relación que la familia Aróstegui había venido manteniendo desde la Edad Media con los reyes castellanos se había visto afianzada con la participación en la guerra de Granada, de su abuelo, Martín Pérez de Aróstegui, llamado el Viejo de Vergara y reforzada por las mercedes que los sucesivos monarcas les fueron concediendo. La línea de este linaje que se asienta en la antigua capital nazarí, se inicia con su abuelo y se consolida con su padre (de igual nombre) que vivió en la villa de El Padul, muy cerca de

3. Acz, Sec. 1. Currículum y honores, Leg. 20.3, Entre otra documentación, con fecha de 5 de agosto de 1617 se conserva el título a favor de D. Antonio de Aróstegui de la Encomienda de San Coloiro.

4. En las últimas décadas se han publicado importantes trabajos sobre el reinado de Felipe III, tratando muy diversos aspectos, de los que pueden servir de ejemplo los de Ildefonso Pulido Bueno, La Real Hacienda de Felipe III, Artes Gráficas Andaluzas, Huelva, 1996; los que han versado sobre las personalidades de los validos de su tiempo, Francesco Benigno, La sombra del rey. Validos y lucha política en la España del siglo XVII, Alianza, Madrid, 1994. Antonio Feros CArrasco, El Duque de Lerma. Realeza y privanza en la España de Felipe III, Marcial Pons, Madrid, 2002. Recientemente se ha culminado con una gran obra de conjunto: Jose Martinez Millan y Maria Antonietta Visceglia (dirs.), La monarquía de Felipe III, Fundación Mapfre Tavera, Madrid, 2007, 4 vols. 
Granada. Sin embargo, su hijo, don Antonio, como muchos otros nobles del momento se establece en Madrid para, como sabiamente expone Domínguez Ortiz, formar parte de esa "dorada servidumbre de Palacio» y estar así en las mejores condiciones para negociar y obtener cargos; algo que sería del todo imposible a «los que se encastillaban en sus pequeñas cortes provincianas».

$\mathrm{Su}$ ascensión comenzaría con el nombramiento como secretario del rey en marzo de 1600 a partir de esta fecha ostentará varias secretarías distintas hasta su muerte. De la Secretaría de Guerra pasará en 1606 a la del Norte y tras la muerte de Andrés de Prada a la Secretaría de Italia, cuyo título se firmó en San Lorenzo de El Escorial en septiembre de 1612. Es entonces cuando recibe el hábito de la Orden de Santiago que proclamaba tan orgulloso en la cabecera de su testamento. Con el cambio de monarca en 1621 no se produjo una alteración significativa en el puesto de Aróstegui que siguió ocupando la misma secretaría con Felipe IV. ${ }^{6}$

Sobre esto el testamento de Antonio de Aróstegui puede ayudar a esclarecer un poco cuál sería el ámbito de relaciones que este mantendría con el entorno más inmediato de la casa del rey, así como alguna de las misiones que se le hubieran encomendado. Ya que en este documento se pueden observar, como los intereses de su otorgante se encuentran repartidos equitativamente entre lo que se tomarían como las preocupaciones de un hombre de su tiempo. Y básicamente se van a centrar en dos grandes proyectos inconclusos que proyectarían su fama a la posteridad, como se verá más adelante. Pero también una parte importante de esta escritura de últimas voluntades y prácticamente la totalidad del codicilo que otorga posteriormente, se va a referir a algunos asuntos de estado que quedan pendientes de resolución. No resulta muy explícito don Antonio en cuanto a estos, ya que los menciona como «cosas muy secretas de su magestad» y suele ceñirse a señalar cantidades de dinero recibidas, su empleo en pagos efectuados y el montante que le resta y que por tanto ha de justificar. Como ocurre con cinco mil ducados castellanos que le entregó en agosto de 1620 el embajador en Génova, don Juan de Vivas, y de los cuales dispone la devolución de los que no ha gastado.

Nombra como albaceas testamentarios además de a su esposa, a su hermano Martín y a un canónigo de la catedral de Granada, el doctor Salinas de Mercado, a varios personajes que como él residían en Madrid y compartían labores burocráticas y servicios para el monarca. Designa a Juan de Ciriza, el que fuera compañero en las tareas de la Secretaría de Estado con Felipe III, y que acabaría sucediéndole. También a Andrés de Prada, que creemos será el sobrino del que había sido su antecesor en la Secretaría de Italia. Menciona a un tal Diego Francos de Garnica, que suponemos se trata del que por esas fechas ostentó

5. Antonio Domínguez Ortiz, La sociedad española en el siglo XVII, Universidad de Granada, Granada, 1992, vol. I, p. 218.

6. José Antonio Escudero, Los secretarios de estado y del despacho. (1474-1724), Instituto de Estudios Administrativos, Madrid, 1976, pp. 230-232. 
el titulo de alcalde de Casa y Corte y otro albacea será Sancho de Ceniceros. Ahora bien, estos dos últimos debieron ser personajes cercanos a Antonio de Aróstegui, y que también estuvieron al servicio del rey, ya que en una de sus mandas testamentarias, le pide a Felipe IV que se acuerde de ellos destacando el buen trabajo y el modo en que han cumplido con sus obligaciones y como así serían ejemplo para otros.

Da la impresión que los albaceas testamentarios que designa responden a la necesidad de que los encargos que les dejaba se llevaran a cabo de una forma eficaz al quedarse por resolver en lugares muy distintos de la geografía peninsular. En Madrid, el círculo de amistades más cercano sería el de personajes, que como él, se habían ocupado de labores administrativas al servicio de la Corona, en el espacio político de decisión próximo al rey. ${ }^{7} \mathrm{Y}$ de igual forma que Aróstegui, discreta y modestamente, sin alcanzar las grandes cotas de poder que tuvieron algunos como validos, se hicieron merecedores de distinciones y prebendas reales, que si bien no les han hecho ocupar una posición de privilegio que otros detentaban, tampoco les colocó bajo la sombra de la sospecha y la especulación de las intrigas cortesanas de su época. Aun así, fueron lo suficientemente hábiles para incrementar su patrimonio e invertirlo en el bienestar familiar y la perpetuación de su nombre y su linaje. ${ }^{8}$

La posible actividad diplomática de don Antonio de Aróstegui a consecuencia de su cargo le pondría en contacto con los embajadores venecianos cuyos testimonios ha estudiado Gil Sanjuán. Sin embargo, estos apenas lo mencionan más que para informar que además de Juan de Prada «fue nombrado un segundo secretario, Aróstegui, de inferior capacidad que el anterior». ${ }^{9}$ No se entienda esto como un descrédito a su competencia para el puesto, sino más bien, el que se le tenían asignadas tareas de menor responsabilidad.

Curiosamente es Francisco de Quevedo, quien aporta una particular y perspicaz visión de la figura de Antonio de Aróstegui al servicio del rey. En su obra «Grandes anales de quince días», clave según la califican los expertos, ${ }^{10}$ para entender los acontecimientos acaecidos entre 1621-1623 en la historia de España, hace mención de la muerte del secretario Aróstegui. Aunque breves, sus palabras pudieran ser de lo más certeras para describir su talante y

7. Carmen Bolaños Mejías, «Fracaso de la reforma institucional a finales del reinado de Felipe III», Anuario de Historia del Derecho Español, Lxxıv (2004), pp. 659-684. Analiza de un modo muy interesante el modo en que la nobleza hubo de especializarse para mantenerse en el círculo de influencia del rey y como asumió sus nuevas tareas administrativas con la intención de conservar su posición y estatus económico.

8. María IsAbel Ostolaza Elizondo, «El acceso de los navarros a la administración castellana: el caso de Tristán y Juan de Ziriza», Príncipe de Viana, 220 (2000), pp. 433-448. Es destacable el paralelismo que se puede encontrar entre Juan de Ciriza y Antonio de Aróstegui. Ambos discretos secretarios del rey, patronos de conventos de la orden agustina, titulares de mayorazgos que al morir sin descendencia recayeron en sus sobrinos, con hermanos que tuvieron cargos en la administración real.

9. Joaquín Gil Sanjuán, «Perfil político de los consejeros de estado de Felipe III», Baetica. Estudios de Arte, Geografía e Historia, 24 (2002), pp. 339-354, p. 344. No lo incluye en la relación de consejeros que los embajadores vénetos debían considerar más relevantes.

10. Vicente Roncero López, «Los Grandes anales de quince días: Literatura e historia», RILCE. Revista de Filología Hispánica, 9 (1993), pp. 56-72. 
valoración en la política de la Corte cuando dice «que debió mucho crédito a su silencio, y mucha estimación a su reposo». ${ }^{11}$

Sin duda sería esa labor callada y fiel de Antonio de Aróstegui durante años, la que explica que en esta, su escritura última, se atreva a recordar al rey que es continuación de la llevada a cabo por su familia durante generaciones y le capaciten para pedirle que se digne en hacerle alguna merced a su esposa, a su hermano y a su sobrino (el hijo de su hermana), argumentando que en ese largo tiempo no ha «acrecentado su casa considerablemente». A pesar de esta advertencia y casi alarde de honradez a la que alude con estas palabras, don Antonio se había hecho con un considerable patrimonio que además de tierras y distintos inmuebles tanto en Granada como en Madrid, incluía los derechos sobre las alcabalas de El Padul y un oficio de fiel ejecutor en Guadahortuna. De los que una parte importante se debían a concesiones reales, como él mismo declara en su testamento cuando dispone su traspaso en la sucesión de sus hermanos en caso de morir él sin descendencia legítima. ${ }^{12}$

\section{Antonio Aróstegui, el hombre piadoso}

Este documento comienza con el proceder habitual con que se intenta demostrar la capacidad legal necesaria para otorgarlo, de ahí que repita su aptitud como persona sana y, lo más importante, hallarse «en mi memoria entendimiento entero y juicio natural». Tras esto realiza la invocación piadosa que siempre encontramos en estas escrituras en las que declara aceptar la muerte como un designio divino y añade que espera le llegue «en el mejor estado que pudiere para mi salvación». De este modo no solo está cumpliendo un requisito estrictamente legal, sino que a la vez reconoce ese objetivo último que alienta a todo fiel cristiano. Para ello se encarga de hacer su debida profesión de fe católica y de nombrar una buena asistencia comenzando por la intercesión de la Virgen, de quien convenientemente recuerda entre otros dones que fue concebida sin pecado y continuando con una larga lista de santos y santas: «para que mediante su intercesión sea mi fin principio de la vida eterna».

A pesar de estas formulas piadosas y de sus pretensiones escatológicas, un atisbo de afán práctico aparece cuando anuncia tras las invocaciones divinas: «hago y ordeno este mi testamento cerrado ultima y postrimera voluntad en descargo de mi conciencia» y a partir de ahí expone el característico reparto

11. Francisco Quevedo Y Villegas, «Grandes anales de quince días», Obras inéditas, Imprenta de Sancha, Madrid, 1794, p. 114.

12. En su testamento señala que el rey le hizo merced de dos regimientos en El Padul, el oficio de fiel ejecutor en Guadahortuna y el sitio de Santa Fe a dos leguas de Granada. EnRIQue Soria Mesa, La venta de señoríos en el Reino de Granada bajo los Austrias, Universidad de Granada, Granada, 1995, p. 149. Nos informa que la compra de las alcabalas a la Corona se produjo en 1613 y que con estas se incrementó el mayorazgo que recaía en su persona, en el que se incluían dos suertes de hacienda, el oficio de escribano y dos de regidor en la villa de El Padul. 
de bienes que ha de iniciarse obligatoriamente devolviendo el alma a Dios y el cuerpo a la tierra. Lo que inevitablemente le conduce a la disposición de su enterramiento, designando a la ciudad de Granada como el lugar en que definitivamente deberían colocarse sus restos tras un periodo de depósito en una iglesia madrileña.

Don Antonio de Aróstegui encargará a sus albaceas los asuntos concernientes al traslado de su cuerpo a la bóveda de la capilla mayor del convento de los agustinos descalzos, del que había asumido el patronato y todos los aspectos que conllevaba el ritual de su entierro y memorias post mortem. En esto, y a la luz de los estudios que sobre religiosidad y ritual funerario barroco se han publicado en las últimas décadas se puede juzgar como un hombre de su tiempo. De acuerdo a la calidad de su persona debía llevarse a cabo no solo su sepelio, sino incluso la celebración de oficios en su memoria.

Solicita un entierro con «pompa moderada y no demasía» ya que entiende que es mejor invertir en misas y otros sufragios que hayan de revertir, en lugar de su representación pública, en la salvación de su alma. A la par que confiesa su firme creencia en la existencia del purgatorio y en el valor de las indulgencias, demanda a sus herederos que mientras vivan cada año tomen una bula de difuntos por él. Mandará la habitual misa y vigilia cantada y el novenario de misas en los días inmediatos a su entierro. Quiere que se digan trescientas misas en altares privilegiados de la villa de Madrid y dos mil más donde dispongan sus albaceas, siempre que se digan con la mayor brevedad posible. Conoce la legislación eclesiástica que le obliga a dejar la cuarta parte de estas misas en su parroquia, pero no se aleja de los parámetros de su época, y ordenará doscientas misas por las ánimas del purgatorio, por las de sus familiares difuntos y por aquellas de los más necesitados para de este modo, tal y como él mismo declara, obtener una intercesión privilegiada ante Dios. Durante el año inmediato a su fallecimiento pide que le cubran su sepultura y pongan cera mientras se celebre misa mayor los domingos y días de fiesta y el último día de este año se celebre un aniversario con vigilia, responso y sermón.

También dejará una importante cantidad de dinero que debe ir como legado a sufragar la cera que alumbre el santísimo en su parroquia, a algunas instituciones hospitalarias y conventos, a la iglesia de San Miguel de Madrid, que debía estar en fase de construcción en esos años, ya que expresamente menciona que si la obra está acabada se emplee en decoración para la imagen de Nuestra Señora del Populo que se adora en ese templo. Obviamente no se olvidará de favorecer a las iglesias del solar de procedencia familiar, como la parroquia de San Pedro de Vergara, a la de El Padul en Granada y muy especialmente a la de los padres agustinos descalzos en la capital granadina de la que es patrón, como se citará más adelante. Dispondrá que a su costa se dé un vestido de luto a todos aquellos criados que estén en el servicio de su casa cuando muera además de un legado monetario. Reparte algunos bienes entre el personal que debía tener más cercano o desasistido y libera a sus esclavos. 
Como era habitual, ordena a sus albaceas que hagan inventario y almoneda de sus bienes para ir saldando deudas, los pagos de su entierro, misas y legados piadosos e incluso relaciona en varias ocasiones que tiene bajo custodia los papeles de los títulos y cargos que ostenta, escrituras y capitulaciones entre otros del patronato de los frailes agustinos de Granada, así como un memorial de sus bienes. Hace especial hincapié en que no se toque nada de las cosas de su esposa doña Agustina de Yuramendi.

\section{SU RELACIÓN CON GRANADA}

Don Antonio de Aróstegui mantendrá gracias al patronato de la iglesia de los agustinos descalzos en el granadino barrio del Albaicín, una conexión con la antigua capital nazarí que vendrá a afianzar la que se había iniciado tras la conquista de Granada con las concesiones que los Reyes Católicos habían hecho a su abuelo y a su padre. Al igual que había sucedido con otros hidalgos que habían participado en la guerra, los antecesores de don Antonio se habían hecho merecedores de algunos favores por parte de los monarcas, como una explotación en Guadahortuna, a la que dieron el nombre de su tierra natal en Guipuzcoa, y a la que todavía se conoce como el Cortijo de Vergara y heredades en la villa de El Padul. En este pequeño pueblo se establecieron sus abuelos y su padre, don Martín cuya valerosa actuación en la rebelión de los moriscos le sirvió para seguir acumulando méritos ante Felipe II, quien le concedió una bordura decorada con cabezas de moros a su escudo de armas, en recuerdo de la personal gesta. ${ }^{13}$

A partir de ahí comenzará una relación con la pequeña localidad granadina que le llevará no solo a dejar limosna a su iglesia parroquial o mantener y acrecentar las fundaciones de misas que ya habían hecho sus abuelos don Martín Pérez y doña Isabel Regidora y Basurto, sino a reedificar con mayor esplendor la que había sido residencia familiar hasta convertirla en una casa noble. Precisamente este es uno de los proyectos más interesantes que aborda el testamento de Don Antonio. Sus pretensiones sin duda, eran la de levantar el edificio más importante del pueblo, con el que se aseguraría la permanencia en la memoria colectiva y haría pública ostentación de su rango. Este cometido concretamente lo pondrá en manos del doctor Salinas, que había actuado como administrador suyo y a quien parece dejar al mando, ya que señala expresamente que se sigan sus órdenes y las trazas tal y como ya se han comenzado.

Ahora bien, la idea es mucho más ambiciosa de lo que podía parecer a primera vista. Ya que no se limita a la conclusión de las obras de una gran casa, sino que pretende urbanizar toda la zona colindante que es de su propiedad, a

13. María Angustias Moreno Olmedo, Heráldica y genealogía granadinas, Universidad y Ayuntamiento de Granada, Granada, 1989, pp. 43-44. 
la que llevaría agua, embellecería mediante obras de ornato público y dotaría con huertos para revalorizarla. Después se deslindaría en una serie de solares en los que construir viviendas, tanto para los vecinos de El Padul como para los que vinieran de fuera, y así pudieran asentarse con mayor facilidad en la villa, que de este modo experimentaría un crecimiento de población. ${ }^{14}$

La idea de don Antonio de Aróstegui es la de promover la urbanización de una amplia superficie construyendo casas que se alquilaran o se transmitieran cargando su propiedad con un censo abierto o perpetuo. Ahora bien, pretende que las rentas que se generasen de esta actividad se reuniesen para poder financiar una fundación piadosa, que se dedicaría entre otras actividades a casar huérfanas del pueblo. Es decir, a reunir la dote suficiente para que pudieran contraer matrimonio chicas sin posibilidades elegidas por una comisión en la que estarían el patrón designado por él, el beneficiado de la parroquia y el concejo de El Padul. Además, deberían reservar la cantidad de cuarenta ducados al año como salario de un maestro de escuela que enseñe a los niños y niñas del lugar. Su educación debe pasar por lo que en aquellos momentos se estimaba básico y suficiente: leer, escribir, contar, doctrina cristiana, ayudar en misa; para que de ese modo se instruyesen en la fe y se aplicasen en la virtud. También deben prever de estas rentas, la cantidad necesaria para un alojamiento en que hospedar a los peregrinos que pasasen por la villa. Dejando la gestión de esta tarea, como obra de misericordia, al cura párroco.

La misericordia envuelve con sus buenas intenciones de hacer «obra pública en utilidad de los vecinos» lo que en su tiempo debió idearse como una promoción moderna y pionera en la provincia de Granada y que en términos actuales se tildaría sin muchas contemplaciones como pura actuación inmobiliaria. Sin embargo, el que una parte de sus beneficios se utilizasen para dotar a huérfanas y rescatar cautivos, que corrían el riesgo de «perderse» vuelven a colocar a don Antonio entre los piadosos fieles que buscaban emplear parte de sus riquezas en su futurible salvación eterna.

Otra conexión de don Antonio con Granada será la que conlleve el patronato del convento que los religiosos agustinos descalzos estaban por construir en el núcleo del barrio del Albaicín. Esta es una información sobradamente conocida desde que se ha recogido en algunas crónicas sobre la Iglesia granadina. Como hizo en 1639 Francisco Bermúdez de Pedraza en su Historia eclesiástica. El capítulo treinta y ocho de la cuarta parte de este texto se dedica íntegramente a la fundación de este cenobio y a la participación en el mismo de Antonio de Aróstegui y de sus sucesores en el patronato. Ya en estas fechas se aportan algunos datos básicos sobre las circunstancias en que se lleva a cabo dicha fundación. Como es propio del espíritu autoencomiástico de este

14. Ana María Jiménez Garnica, «Urbanismo y Salud Pública. El Paseo del Prado madrileño: Un ejemplo de saludable armonía entre la Naturaleza y el Arte en el espacio urbano», Anales de la Real Academia Nacional de Farmacia, vol. 68 (2002), pp. 157-205. Aunque se desconoce si los intereses de Antonio de Aróstegui iban encaminados hacia la mejora de la salud pública, lo que sí debió tener en cuenta son los ejemplos de urbanidad llevados a cabo en Madrid mientras tuvo allí su residencia. 
tipo de literatura su autor relaciona los importantes cargos y honores que aunaba su patrón. También apunta las especiales circunstancias que concurren en el solar que será asiento de dicho convento, el del antiguo hospital de la Resurrección o de los moriscos, tras haber sido estos expulsados y confiscados sus bienes por la Corona. Además, adelanta cómo se sucedería la titulatura del patronato dentro de la casa de los Aróstegui tras la temprana muerte de su primer patrón en 1623, recayendo en su hermano Martín primero y después en sus sobrinos, hijos de su única hermana. ${ }^{15}$

Se pueden poner muchas esperanzas en extraer una valiosa información sobre las circunstancias que incurrieron en la promoción y materialización de esta nueva fundación religiosa en la Granada barroca de la lectura del testamento. Ya que deberían ser muchas las disposiciones que respecto a ella debiera prever don Antonio en calidad de patrón, de un convento que en la fecha de su muerte todavía no había comenzado, ni tan siquiera a abrir sus cimientos, y posiblemente ocupaba las antiguas y desahuciadas fábricas del hospital de los moriscos.

Sin embargo, básicamente lo que hace es disponer la dotación económica que anualmente ha de entregarse al convento para la construcción de la iglesia nueva, a cuya capilla mayor pretende que sean trasladados sus restos, los de sus padres y los de sus abuelos y de la que se pagarán también los ornamentos para su servicio y la ejecución de un retablo y una reja. De igual modo, utiliza esta escritura para señalar los oficios religiosos que han de celebrarse en su memoria y en la de sus familiares difuntos, así como los privilegios debidos por parte de los frailes: darles tribuna, reconocimiento en la paz, vela en la Candelaria, palma el Domingo de Ramos y la llave del Santísimo Sacramento... y resumiendo con sus palabras «y todo lo demás que sea costumbre y sea con los otros patronos de conventos».

Sobre las vicisitudes de la fundación agustina en la ciudad se ha de utilizar la obra que el fray Pedro de Jesús escribió con motivo de la dedicación de su nuevo templo a la advocación de Nuestra Señora de Loreto en 1695. En esta no solo se describen, tal y como cita su título, las fiestas conmemorativas de tal evento, sino que se hace una prolija relación de la historia del convento y de las dificultades para su asentamiento en Granada. Además de incluir una detallada descripción del monasterio, que pasa por una concienzuda enumeración tanto de sus capillas y altares como de las excelencias de su arquitectura y decoración. ${ }^{16}$

15. Francisco Bermúdez De Pedraza, Historia eclesiástica de Granada, Universidad de Granada, Granada, 1989, Cuarta parte, cap. XxxviII, fols. 283v-284.

16. F. Pedro De Jesús, Templo nuevo de Agustinos descalzos de Granada y suntuosas fiestas que se celebraron a su dedicación con el titulo de Nuestra Señora de Loreto, Imprenta de Francisco Gómez Garrido, Granada, 1695. 
Una de las dotaciones más especiales que dejó al convento como su patrón debió ser el legado que les hizo de reliquias e imágenes que tenía en el oratorio de su casa. ${ }^{17}$ Toma la precaución de recordar en su testamento que estas preciadas posesiones se dividan en dos, reservando una mitad para su esposa. Esta podría disponer de ellas según su voluntad, al igual que sobre el lugar en que ordenará su futuro enterramiento. Aspecto este que no aclara suficientemente en el testamento, aunque parece obvio, que si optaba por otro lugar distinto a la capilla mayor de los agustinos granadinos es muy probable que su parte acabara lejos de esta fundación.

Aun sin conocer exactamente el destino de la parte que quedaba para su viuda, el número de reliquias que acabaron en el convento de los agustinos fue muy importante, tal y como relata la crónica de fray Pedro anteriormente citada. Y estas, valoradas como tales, se colocaron en la capilla mayor de la nueva iglesia. ${ }^{18}$ Desafortunadamente no informa de cuáles de las imágenes que adornaban el templo pudieran proceder de la donación realizada por su patrón. Quedándose este como un campo abierto para futuras investigaciones que incidan en recabar la información que ayude a conocer las obras que conformaron su oratorio privado o que ornaban su casa, y que posteriormente llegaran hasta Granada.

Algo igual ocurre con las posibles donaciones a la iglesia de El Padul que si bien se mencionan en su testamento no aclara la naturaleza de las mismas. Ya que expresa su voluntad de que se haga un inventario de bienes que tiene en la casa de este lugar y de las cosas que ha dado o dará a la iglesia. Lo que no implica más que la intención de dejarle algún legado además de los que ya habría realizado y de los que no aporta detalle alguno. Es por tanto terreno este para la hipótesis, como la planteada sobre el posible patrocinio del retablo mayor de esta parroquia por parte de Martín de Aróstegui, padre de don Antonio. ${ }^{19}$ Lo que sí explica, es que además de algunas limosnas y el acrecentamiento de anteriores fundaciones piadosas de su familia, «hize traer indulto de su Santidad para altar previlegiado donde se saca anima» para el altar mayor de esta iglesia. Lo que sin duda es una muestra más del fuerte vínculo que había establecido con esta villa granadina.

17. Tras consultar la documentación que se conserva en el Archivo Secreto Vaticano en la Sección de la Nunciatura de Madrid, leg. 340, fol. 46 se puede estudiar parte de la correspondencia que trataba la autorización para poder tener un oratorio privado en que celebrar misa. Como argumenta que este es un privilegio que entre otros ha obtenido ya su colega Ciriza y como finalmente con fecha del 19 de marzo de 1616 se le concede el permiso con las limitaciones y precauciones habituales, como que lo mantenga decente, que lo apruebe el Ordinario... entre otras. Pero en esta no se aporta dato alguno sobre la advocación que tuviera o las imágenes que lo embellecerían.

18. F. Pedro De Jesús, Templo nuevo de Agustinos, 1695, pp. 32-33 hace una numerosa relación de las reliquias y en la p. 54 explica que se colocaron en unas urnas en el retablo del altar mayor.

19. José Manuel Gómez-Moreno Calera, «La herencia de Machuca en la pintura del renacimiento granadino: el retablo de San Francisco de El Padul y las tablas del primitivo sagrario», Cuadernos de Arte de la Universidad de Granada, 25 (1994), pp. 25-26, pp. 32-33. 


\section{Archivos Consultados}

AHDGR: Archivo Histórico Diocesano de Granada ACZ: Archivo de la Casa Zabala

ASV: Archivo Secreto Vaticano 